\title{
MicroRNA-199a-5p suppresses migration and invasion in oral squamous cell carcinoma through inhibiting the EMT-related transcription factor SOX4
}

\author{
DONGYI WEI $^{1}$, WEIXIN WANG ${ }^{1}$, BAOHONG SHEN $^{1}$, YANJUN ZHOU $^{2}$, \\ XIAODONG YANG ${ }^{2}$, GUANGJIAN LU ${ }^{2}$, JIANBIN YANG ${ }^{1}$ and YUEBAO SHAO ${ }^{1}$ \\ ${ }^{1}$ Department of Oral and Maxillofacial Surgery, ${ }^{2}$ Clinical Laboratory, \\ The First Affiliated Hospital of Xinxiang Medical University, Weihui, Henan 453100, P.R. China
}

Received July 17, 2018; Accepted April 19, 2019

DOI: $10.3892 / \mathrm{ijmm} .2019 .4174$

\begin{abstract}
MicroRNAs (miRs) are small, non-coding RNAs that can act as oncogenes or tumor suppressor genes in human cancer. Recent studies have revealed that miR-199a-5p is abnormally expressed in various types of human cancer; however, the potential role of miR-199a-5p in oral squamous cell carcinoma (OSCC) remains elusive. The present study investigated the role of miR-199a-5p in OSCC cells and explored the potential molecular mechanism. Reverse transcription-quantitative polymerase chain reaction was used to measure miR-199a-5p expression in OSCC tissues and adjacent normal oral epithelial tissues. Cell invasion and migration were evaluated using Transwell invasion and wound-healing assays in OSCC cells post-transfection with miR-199a-5p mimics or negative control mimics. In addition, a luciferase reporter assay was conducted to identify the target gene of miR-199a-5p in OSCC cells. The results demonstrated that miR-199a-5p expression was significantly downregulated in OSCC tissues and cell lines, and was associated with tumor progression in OSCC. Furthermore, overexpression of miR-199a-5p inhibited cell invasion and migration, and blocked the epithelial-mesenchymal transition (EMT) cascade. Notably, the results revealed that the EMT-related transcription factor SRY-box 4 (SOX4) was a direct target gene of miR-199a-5p, as determined by the direct binding of miR-199a-5p with the 3'-untranslated region of SOX4. In addition, knockdown of SOX4 by small interfering RNA-SOX4 suppressed proliferation, migration and invasion of OSCC cells. Conversely, overexpression of SOX4 rescued
\end{abstract}

Correspondence to: Dr Yuebao Shao, Department of Oral and Maxillofacial Surgery, The First Affiliated Hospital of Xinxiang Medical University, 88 Jiankang Road, Weihui, Henan 453100, P.R. China

E-mail: yuebaoshaoybs@163.com

Key words: microRNA-199a-5p, oral squamous cell carcinoma, metastasis, epithelial-mesenchymal transition cascade, SRY-box 4, tumor suppressor the suppressive effects of miR-199a-5p on cell migration and invasion. Collectively, these data indicated that miR-199a-5p may inhibit the migration and invasion of OSCC cells via targeting the EMT-related transcription factor SOX4, thus suggesting that miR-199a-5p may serve as a prognostic biomarker and therapeutic target in the treatment of OSCC.

\section{Introduction}

Oral squamous cell carcinoma (OSCC), which is the sixth most common type of human cancer worldwide, is an aggressive epithelial malignancy (1). Each year $>300,000$ new cases are reported and $\sim 9,000$ individuals succumb to this disease in the United States. The 5-year survival rate is $\sim 50 \%$, even though there have been some advancements in therapeutic regimens (2). The lack of characteristic symptoms in the early stages and the absence of non-invasive screening tests leads to high mortality in patients with OSCC (3). In addition, local tumor recurrence and metastasis are key factors in the development of OSCC (4). Therefore, there is an urgent need to identify and develop novel strategies for the clinical diagnosis and treatment of patients with OSCC.

SRY-box 4 (SOX4) is a 47-kDa protein and a member of the SOX family of transcription factors, which has an important role in embryonic development and cell-fate determination during organogenesis (5). SOX4 has been reported to be upregulated in various types of cancer, and SOX4 aberrant expression may regulate cellular transformation, cell survival and metastasis (6-8). Numerous studies have reported that SOX4 acts as an oncogene in various types of cancer, including prostate cancer, hepatocellular carcinoma and lung cancer (9-11). In addition, SOX4 has been demonstrated to induce epithelial-mesenchymal transition (EMT) $(12,13)$, which serves a key role in tumor metastasis and is associated with tumor recurrence (14).

MicroRNAs (miRNAs/miRs) are a class of small non-coding RNAs (length, 21-23 nucleotides), which negatively modulate gene expression at the post-transcriptional level through inhibiting translation or inducing RNA degradation $(15,16)$. miRNAs are associated with various physiological and pathological processes, including cellular metabolism, 
proliferation, differentiation and death (17). Accumulating evidence has revealed that miRNAs are dysregulated and have key roles in several types of cancer, and can act as tumor suppressor genes and potent oncogenes (18). Notably, miRNA dysregulation is considered to be associated with the occurrence and development of OSCC (19). Previous studies have demonstrated that miR-199a-5p serves a key role in tumor development via modulation of tumor suppressor genes or oncogenes in various types of cancer, including hepatocellular cancer, gastric cancer and ovarian cancer (20-22). He et al revealed that miR-199a-5p is upregulated in gastric cancer tissues and functions as an oncogene in gastric cancer (22). Furthermore, upregulation of miR-199a-5p has been recognized as a signature for poor prognosis in uveal melanoma and it is associated with a high metastatic risk (23). Conversely, Zhong et al reported that miR-199a-5p is downregulated in prostate adenocarcinoma, and overexpression of miR-199a-5p attenuates cell motility, proliferation and tumor angiogenesis in prostate adenocarcinoma cell lines (24). In addition, miR-199a-5p has been identified to function as an antitumor miRNA in head and neck squamous cell carcinoma cell lines (25). However, the molecular mechanism underlying the role of miR-199a-5p in the development of OSCC remains unclear.

The present study performed reverse transcription-quantitative polymerase chain reaction (RT-qPCR) to detect the expression levels of miR-199a-5p in OSCC tissues and explored the molecular mechanism underlying the biological function of this miRNA. The results revealed that miR-199a-5p is downregulated in human OSCC tissues and cell lines, and its expression in OSCC tissues with lymph node metastasis is lower than that in tissues without lymph node metastasis. In addition, the present findings revealed that miR-199a-5p inhibits cell invasion and migration in OSCC cells through targeting the oncogene SOX4, thus suggesting that miR-140-5p may possess potential value in the clinical diagnosis and treatment of OSCC.

\section{Materials and methods}

Patients and tissue samples. The OSCC tissues and adjacent normal oral epithelial tissues were collected from 40 patients with OSCC at the Department of Oral and Maxillofacial Surgery, The First Affiliated Hospital of Xinxiang Medical University (Weihui, China) between November 2015 and January 2016. The patients enrolled in this study did not receive radiotherapy or chemotherapy prior to surgical resection. All tissue samples were confirmed by pathological examination. All OSCC tissues and corresponding normal oral epithelial tissues were frozen in liquid nitrogen and stored at $-80^{\circ} \mathrm{C}$ until further use. Patient characteristics are presented in Table I. The present study was approved by the Ethics Committee of The First Affiliated Hospital of Xinxiang Medical University and all patients provided written informed consent.

Cell culture. The human OSCC cell lines HSC-2, CAL-27, Tca8113 and SCC-4 were obtained from the American Type Culture Collection (Manassas, VA, USA). The cells were grown in RPMI 1640 medium (Gibco; Thermo Fisher Scientific, Inc., Waltham, MA, USA) supplemented with $10 \%$ fetal bovine serum
(FBS; Sigma-Aldrich; Merck KGaA, Darmstadt, Germany), $100 \mathrm{IU} / \mathrm{ml}$ penicillin and $100 \mathrm{mg} / \mathrm{ml}$ streptomycin at $37^{\circ} \mathrm{C}$ in a humidified atmosphere containing $5 \% \mathrm{CO}_{2}$. The normal human oral keratinocytes (HOK) (ScienCell Research Laboratories, Inc., San Diego, CA, USA) were grown in oral keratinocyte medium (Invitrogen; Thermo Fisher Scientific, Inc.).

Cell transfection. miR-199a-5p mimics/inhibitor and the corresponding negative control (NC) sequences (mimics/inhibitor NC) were synthesized by Shanghai GenePharma Co., Ltd. (Shanghai, China). Small interfering (si)RNA sequences, si-SOX4 and NC si-Scramble, were purchased from Ambion (Thermo Fisher Scientific,Inc.).The oligonucleotides sequences as the following: miR-199a-5p mimics, sense 5'-CCCAGUGUU CAGACUACCUGUUC-3'; mimics NC, sense 5'-CGGTGU GUUCAGACUACCUGUUC-3'; miR-199a-5p inhibitor, sense 5'-AACAGGTAGTCTGAACACT-3'; inhibitor NC, sense: 5'-TAACACGTCTATACGCCCA-3'; si-SOX4-1, 5'-GCA AACGCTGGAAGCTGCTCAAAGA-3'; si-SOX4-2, 5'-TGG AAGCTGCTCAAAGACAGCGACA-3'; si-SOX4-3, 5'-GGA AGCTGCTCAAAGACAGCGACAA-3'; and si-Scramble,: 5'-TGGGTCGACTCAGAACGACGAAACA-3'. For plasmid construction (pcDNA-SOX4), the SOX4 3'-untranslated region (UTR) was cloned into the XhoI and $K p n I$ sites of the pcDNA3.1 expression vector (Invitrogen; Thermo Fisher Scientific, Inc.); an empty pcDNA3.1 vector (pcDNA-vector) used as a control. For transfection, SCC-4 or HSC-2 cells were plated in 6-well plates $\left(2 \times 10^{6}\right.$ cells/well $)$ and were transfected with miR-199a-5p mimics/inhibitor, mimics/inhibitor NC, si-SOX4/si-Scramble or pcDNA-SOX4/pcDNA-vector at a final concentration of $100 \mathrm{nM}$ using Lipofectamine ${ }^{\circledR} 2000$ (Invitrogen; Thermo Fisher Scientific, Inc.), according to the manufacturer's protocol. Subsequently, cells were cultured at $37^{\circ} \mathrm{C}$ in an incubator containing $5 \% \mathrm{CO}_{2}$ for $48 \mathrm{~h}$ after transfection, after which, cells underwent subsequent experiments. Transfection efficiency was assessed using RT-qPCR.

$R T-q P C R$. Total RNA was isolated from tissues and cells using TRIzol ${ }^{\circledR}$ reagent (Invitrogen; Thermo Fisher Scientific, Inc.), according to the manufacturer's protocol. TaqMan Gene Expression Assay and TaqMan MicroRNA Reverse Transcription kits (Applied Biosystems; Thermo Fisher Scientific, Inc.) were used for RT prior to SOX-4 and miRNA detection, according to the manufacturer's protocol. PCR was performed on an ABI PRISM 7300 sequence detection system using a SYBR-Green I Real-Time PCR kit (both Applied Biosystems; Thermo Fisher Scientific, Inc.). PCR amplification was conducted at $95^{\circ} \mathrm{C}$ for $3 \mathrm{~min}$, followed by 35 cycles comprising $95^{\circ} \mathrm{C}$ for $10 \mathrm{sec}, 60^{\circ} \mathrm{C}$ for $30 \mathrm{sec}$ and $72^{\circ} \mathrm{C}$ for 30 sec. U6 served as an endogenous control for miR-199a-5p and GAPDH served as a reference control for SOX4. The following primers were used: miR-199a-5p, forward 5'-TCC CAGTGTTCAGACTACC-3', reverse 5'-TTTGGCACTAGC ACATT-3'; SOX4, forward 5'-CCAGTTCTTGCACGCTGT TT-3', reverse 5'-TGTTGCAAGGTAGGAAGCCA-3'; U6, forward 5'-CTCGCTTCGGCAGCACA-3', reverse 5'-AAC GCTTCACGAATTTGCGT-3'; and GAPDH, forward 5'-AAC GTGTCAGTGGTGGACCTG-3' and reverse 5'-AGTGGG TGTCGCTGTTGAAGT-3'. Fold changes were determined using the relative quantification $\left(2^{-\Delta \Delta \mathrm{Cq}}\right)$ method (26). 
Table I. Association between miR-199a-5p expression and the clinicopathological features of patients with oral squamous cell carcinoma.

miR-199-5p expression

\begin{tabular}{|c|c|c|c|c|}
\hline & & & & \\
\hline Clinical parameters & All cases $(n=40)$ & $\operatorname{High}(\mathrm{n}=16)$ & Low $(n=24)$ & $\mathrm{P}$-value \\
\hline Sex & & & & 0.685 \\
\hline Male & 26 & 11 & 15 & \\
\hline Female & 14 & 5 & 9 & \\
\hline Age (years) & & & & 0.408 \\
\hline$\geq 50$ & 27 & 12 & 15 & \\
\hline$<50$ & 13 & 4 & 9 & \\
\hline Site & & & & 0.604 \\
\hline Buccal mucosa & 22 & 8 & 14 & \\
\hline Non-buccal mucosa & 18 & 8 & 10 & \\
\hline Alcohol use & & & & 0.505 \\
\hline Yes & 25 & 9 & 16 & \\
\hline No & 15 & 7 & 8 & \\
\hline Smoking & & & & 0.897 \\
\hline Yes & 22 & 9 & 13 & \\
\hline No & 18 & 7 & 11 & \\
\hline cTNM stage & & & & 0.064 \\
\hline $\mathrm{I}+\mathrm{II}$ & 9 & 6 & 3 & \\
\hline III + IV & 31 & 10 & 21 & \\
\hline Tumor size $(\mathrm{cm})$ & & & & $0.020^{\mathrm{a}}$ \\
\hline$\geq 2$ & 19 & 4 & 15 & \\
\hline$<2$ & 21 & 12 & 9 & \\
\hline Differentiation & & & & $0.037^{\mathrm{a}}$ \\
\hline Well and moderate & 23 & 6 & 17 & \\
\hline Poor & 17 & 10 & 7 & \\
\hline Lymph node metastasis & & & & $0.003^{\mathrm{b}}$ \\
\hline Present & 28 & 7 & 21 & \\
\hline Absent & 12 & 9 & 3 & \\
\hline
\end{tabular}

${ }^{\mathrm{a}} \mathrm{P}<0.05,{ }^{\mathrm{b}} \mathrm{P}<0.01$. cTNM, clinical Tumor-Node-Metastasis.

Cell invasion assay. Cell invasion assays were performed using 24-well Transwell chambers with polycarbonate membranes (pore size, $8.0 \mu \mathrm{m}$; Corning Inc., Corning, NY, USA). Briefly, SCC-4 or HSC- 2 cells $\left(2 \times 10^{6}\right.$ cells/well) were plated into the upper chambers, which were precoated with Matrigel (BD Biosciences, Franklin Lakes, NJ, USA). After $48 \mathrm{~h}$ at $37^{\circ} \mathrm{C}$, non-invading cells on the upper side of the membrane were removed and invasive cells on the lower surface of the membrane were fixed with $20 \%$ methanol at $4^{\circ} \mathrm{C}$ for $30 \mathrm{~min}$ and stained with $0.1 \%$ crystal violet (Sigma-Aldrich; Merck $\mathrm{KGaA}$ ). The number of invasive cells was counted from six random fields in each well using an IX71 inverted microscope (Olympus Corporation, Tokyo, Japan); images were then captured (magnification, x200).

Cell migration assay. A wound-healing assay was performed to analyze cell migration. Briefly, SCC-4 or HSC-2 cells
( $2 \times 10^{6}$ cells/well) were plated into 6 -well plates. After $48 \mathrm{~h}$ at $37^{\circ} \mathrm{C}$, the migration status was examined by measuring the movement of cells into a scraped area, which was created using a micropipette tip. After 0 or 48 h, cells were fixed in $4 \%$ paraformaldehyde (cat. no. 15714; Electron Microscopy Sciences) for $1 \mathrm{~h}$ at room temperature, and were observed under a microscope. The wounds were analyzed in six random fields using an IX71 inverted microscope (Olympus Corporation; magnification, $x 200)$. The percentage of closure of the denuded area was calculated using ImageJ software (version 1.44; National Institutes of Health, Bethesda, MD, USA).

Cell viability analysis. Cell viability was evaluated using the Cell Counting Kit-8 (CCK-8) assay, according to the manufacturer's protocol. Briefly, SCC-4 or HSC-2 cells were seeded into 96-well plates at an initial density of $5 \times 10^{4}$ cells/well, and were cultured in $100 \mu \mathrm{l}$ RPMI-1640 medium supplemented 
with $10 \%$ FBS. At the specified time points (24, 48 and $72 \mathrm{~h})$, $10 \mu$ l CCK-8 solution (Dojindo Molecular Technologies, Inc., Rockville, MD, USA) was added to each well. Subsequently, the plate was incubated for $1 \mathrm{~h}$ at $37^{\circ} \mathrm{C}$ in an atmosphere containing $5 \% \mathrm{CO}_{2}$ and the absorbance rate was measured at $450 \mathrm{~nm}$ using a microplate reader (Bio-Rad Laboratories, Inc., Hercules, CA, USA). Experiments were performed in triplicate.

Western blot analysis. SCC-4 or HSC-2 cells were lysed as described previously (2) and the protein concentrations were measured using a bicinchoninic acid protein assay kit (Pierce; Thermo Fisher Scientific,Inc.).Protein samples $(30 \mu \mathrm{g})$ were then separated by $10 \%$ SDS-PAGE (Sigma-Aldrich; Merck KGaA) and were transferred onto polyvinylidene difluoride (PVDF) membranes (GE Healthcare Life Sciences, Little Chalfont, UK). The PVDF membranes were blocked in 5\% nonfat milk (Sigma-Aldrich; Merck KGaA) at room temperature for $1 \mathrm{~h}$ and were then incubated with the following primary antibodies at $4^{\circ} \mathrm{C}$ overnight: SOX-4 (1:500; cat. no. ab80261; Abcam, Cambridge, MA USA), E-cadherin (1:1,000; cat. no. sc-7870; Santa Cruz Biotechnology, Inc., Dallas, TX. USA), N-cadherin (1:1,000; cat. no. ab18203; Abcam), fibronectin (1:1,000; cat. no. sc-18825; Santa Cruz Biotechnology, Inc.) and vimentin (1:1,000; cat. no. sc-5565; Santa Cruz Biotechnology, Inc.). $\beta$-actin (1:750; cat. no. A5060; Sigma-Aldrich; Merck KGaA) served as an internal control. Membranes were then incubated with horseradish peroxidase-conjugated goat anti-rabbit or goat anti-mouse IgG secondary antibodies [dilution 1:10,000; cat. nos. GAR0072 and GAM0072; MultiSciences (Lianke) Biotech, Co., Ltd., Hangzhou, China] at room temperature for $2 \mathrm{~h}$. Subsequently, the protein bands were scanned on X-ray film and were visualized using the enhanced chemiluminescence detection system (PerkinElmer, Inc., Waltham, MA, USA). The relative intensity of each band was semi-quantified using Alpha Imager software version 2000 (ProteinSimple, San Jose, CA, USA). The measurements were conducted independently at least three times with similar results.

Luciferase reporter assay. Bioinformatics analysis (TargetScan; www.targetscan.org/vert_72) was used to predict the putative target genes of miR-199a-5p in OSCC cells. The SOX4 3'-UTR encompassing the target sequence for miR-199a-5p was amplified by PCR and cloned into the psi-CHECK-2 Vector (Promega Corporation, Madison, WI, USA) (wild type psi-CHECK-2-SOX4-3'-UTR). Site-directed mutagenesis of the miR-199a-5p target site in the SOX4 3'-UTR (psi-CHECK-2-SOX4-mut-3'-UTR) was performed using the QuikChange II Site-Directed Mutagenesis kit (Agilent Technologies, Inc., Santa Clara, CA, USA). SCC-4 cells $\left(5 \times 10^{4}\right.$ cells/well) were seeded into 96 -well plates and the cells were co-transfected with 400 ng psi-CHECK-2-SOX4-3'-UTR or psi-CHECK-2-SOX4-mut-3'-UTR, and 50 ng miR-199a-5p mimics/inhibitor or the corresponding $\mathrm{NC}$ using Lipofectamine $^{\circledR} 2000$ reagent (Invitrogen; Thermo Fisher Scientific, Inc.). The ratio of firefly to Renilla luciferase was used to normalize relative firefly luciferase activity $48 \mathrm{~h}$ post-transfection, and luciferase activity was measured using the Dual-Luciferase ${ }^{\circledR}$ Reporter Assay system (Promega Corporation), according to the manufacturer's protocol.
Statistical analysis. All statistical analyses were carried out using SPSS software (version 18.0; SPSS, Inc., Chicago, IL, USA). Data are presented as the means \pm standard deviation. Comparisons between two groups were made using Student's t-test. A one-way analysis of variance followed by Tukey's post-hoc multiple comparisons test was used to determine statistically differences among multiple groups. The associations between miR-199a-5p level and clinicopathological features were analyzed using $\chi^{2}$ test. Survival analysis was conducted using the Kaplan-Meier method followed by a log-rank (Mantel-Cox) test. The correlation between miR-199a-5p and SOX4 expression was assessed by Spearman's analyses. $\mathrm{P}<0.05$ was considered to indicate a statistically significant difference.

\section{Results}

miR-199a-5p is downregulated in human OSCC tissues and cell lines. To investigate the association between miR-199a-5p expression and OSCC, RT-qPCR was used to detect miR-199a-5p expression in 40 paired OSCC tissues and adjacent normal oral epithelial tissues. As shown in Fig. 1A, miR-199a-5p expression was markedly downregulated in OSCC tissues compared with in normal oral epithelial tissues $(\mathrm{P}<0.01)$. Furthermore, miR-199a-5p expression was reduced in OSCC tissues with lymph node metastasis $(n=28)$ compared with in tissues without lymph node metastasis $(n=12)(\mathrm{P}<0.01$; Fig. 1B). This study further analyzed the association between miR-199a-5p and the clinicopathological features of patients with OSCC (Table I). To determine the clinical value of miR-199a-5p, the mean expression level of miR-199a-5p was used as a cut-off value to divide 40 patients with OSCC into two groups: The miR-199a-5p high expression group and the miR-199a-5p low expression group. The results revealed that low miR-199a-5p expression in OSCC was associated with lymph node metastasis $(\mathrm{P}=0.003)$, differentiation $(\mathrm{P}=0.037)$ and tumor size $(\mathrm{cm})(\mathrm{P}=0.020)$ (Table I). However, miR-199a-5p expression was not associated with sex, age (years), tumor site, alcohol use, smoking and clinical Tumor-Node-Metastasis stage (27) (Table I). Kaplan-Meier analysis indicated that OSCC patients with low miR-199a-5p expression $(n=24)$ had a poorer overall survival rate compared with patients with high miR-199a-5p expression ( $\mathrm{n}=16)(\mathrm{P}<0.01$; Fig. 1C). In addition, this study further confirmed that miR-199a-5p was markedly downregulated in the OSCC cell lines HSC-2, CAL-27, Tca8113 and SCC-4 compared with in HOK cells $(\mathrm{P}<0.01$; Fig. 1D). The two OSCC cell lines, HSC-2 and SCC-4, with the lowest expression levels of miR-199a-5p, were selected for subsequent analysis in the present study. These data indicated that miR-199a-5p may serve an important role in the development of OSCC.

Overexpression of miR-199a-5p suppresses cell invasion and migration in vitro. To further elucidate the role of miR-199a-5p in OSCC cells, SCC-4 and HSC-2 cells were transfected with miR-199a-5p mimics or mimics NC, and cell invasion and migration were evaluated using Transwell invasion and wound-healing assays, respectively. This study initially evaluated the transfection efficiency of miR-199a-5p mimics and miR-199a-5p inhibitor in SCC-4 and HSC-2 cells. The results revealed that miR-199a-5p expression was 
A

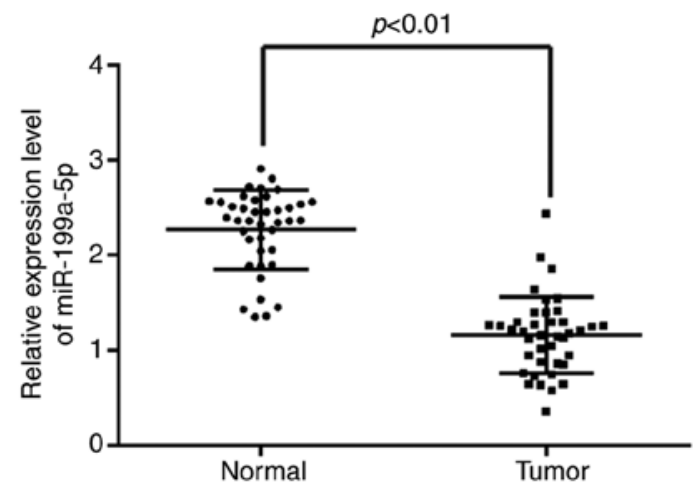

C

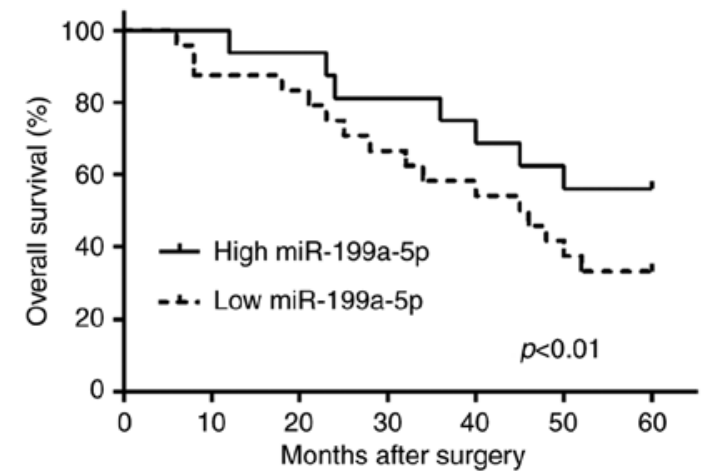

B
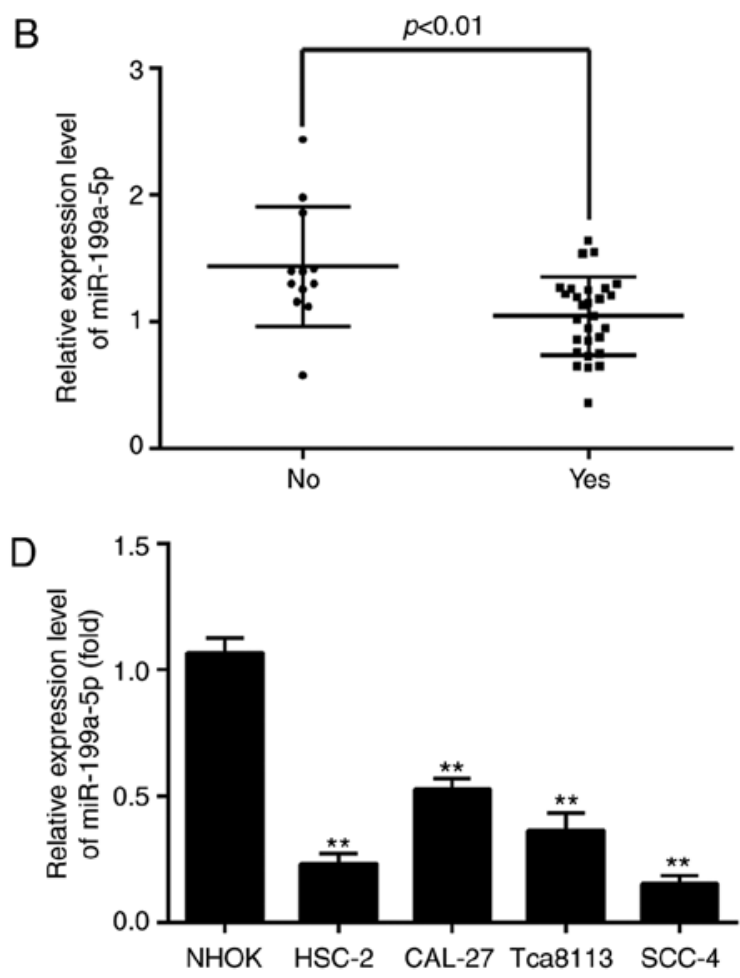

Figure 1. miR-199a-5p is downregulated in human OSCC tissues and cell lines. (A) miR-199a-5p expression was measured using RT-qPCR in OSCC tissues and adjacent normal oral epithelial tissues $(\mathrm{n}=40)$. (B) RT-qPCR was used to detect miR-199a-5p expression in OSCC tissues with lymph node metastasis ( $\mathrm{n}=28$ ) and OSCC tissues without lymph node metastasis $(\mathrm{n}=12)$. (C) Kaplan-Meier survival curve analysis of patients with OSCC (n=40) divided by miR-199a-5p expression. Log-rank test was used for survival analysis. (D) miR-199a-5p expression was detected by RT-qPCR in OSCC cell lines, HSC-2, CAL-27, Tca8113 and SCC- 4 , and in NHOK cells. ${ }^{* *} \mathrm{P}<0.01$ vs. NHOK cells. Data are presented as the means \pm standard deviation of three independent experiments. miR-199a-5p, microRNA-199a-5p; NHOK, normal human oral keratinocyte; OSCC, oral squamous cell carcinoma; RT-qPCR, reverse transcription-quantitative polymerase chain reaction.

markedly upregulated in SCC-4 and HSC-2 cells transfected with miR-199a-5p mimics compared with in cell transfected with mimics NC, whereas transfection with miR-199a-5p inhibitor downregulated miR-199a-5p expression compared with inhibitor NC ( $\mathrm{P}<0.01$; Fig. $2 \mathrm{~A}$ and B). Subsequently, the results revealed that miR-199a-5p overexpression significantly inhibited the invasion of SCC-4 and HSC-2 cells compared with mimics $\mathrm{NC}(\mathrm{P}<0.01$; Fig. $2 \mathrm{C}$ and $\mathrm{D})$. Furthermore, the results further confirmed that overexpression of miR-199a-5p markedly suppressed cell migration compared with mimics $\mathrm{NC}(\mathrm{P}<0.01$; Fig. $2 \mathrm{E}$ and $\mathrm{F})$. These data suggested that miR-199a-5p may exert suppressive effects on cell migration and invasion in OSCC.

Tumor cell invasion and metastasis are tightly correlated with various processes, including EMT. During EMT, epithelial tumors progress to more aggressive metastatic tumors, alongside which the expression of mesenchymal protein markers, including $\mathrm{N}$-cadherin and vimentin, is upregulated, whereas the epithelial protein marker E-cadherin is downregulated (14,28-29). It has been well documented that miRNAs regulate tumorigenesis via modulating EMT in various types of cancer, including OSCC (30-32). The present results demonstrated that miR-199a-5p upregulated the expression levels of E-cadherin, and downregulated $\mathrm{N}$-cadherin, vimentin and fibronectin in SCC-4 and HSC-2 cells (Fig. 2G). Taken together, these results suggested that miR-199a-5p may inhibit cell invasion and migration in OSCC cells via modulating EMT.
miR-199a-5p inhibits SOX4 expression by directly targeting its 3'-UTR in OSCC cells. Bioinformatics analysis revealed that SOX4 may be a potential target gene of miR-199a-5p in OSCC cells (Fig. 3A). Previous studies have reported that SOX4 functions as an oncogene in numerous types of cancer, such as prostate cancer, lung cancer and hepatocellular carcinoma (9-11). Additionally, SOX4 has been identified to serve a key role in EMT and may induce cancer cell metastasis $(1,13)$. Therefore, to further investigate the association between miR-199a-5p and SOX4 in OSCC, SOX4 expression was detected in OSCC tissues and adjacent normal oral epithelial tissues. As shown in Fig. 3B, SOX4 expression was significantly upregulated in tumor tissues compared with in normal tissues $(\mathrm{P}<0.01)$. Correlation analysis revealed that there was a significant negative correlation between miR-199a-5p and SOX4 expression in 40 tumor tissues ( $\mathrm{r}=-0.7441, \mathrm{P}<0.01$; Fig. 3C). Furthermore, overexpression of miR-199a-5p markedly inhibited SOX4 $(\mathrm{P}<0.01$; Fig. 3D), whereas inhibition of miR-199a-5p significantly upregulated SOX4 expression in SCC-4 and HSC-2 cells $(\mathrm{P}<0.01$; Fig. $3 \mathrm{E})$. Luciferase reporter assay revealed that miR-199a-5p markedly inhibited luciferase activity when compared with mimics NC, whereas miR-199a-5p inhibitor significantly enhanced luciferase activity $(\mathrm{P}<0.01$; Fig. 3F). However, miR-199a-5p mimic/inhibitor did not affect luciferase activity in cells transfected with psi-CHECK-2-SOX4-mut-3'-UTR (Fig. 3F). Collectively, 
A

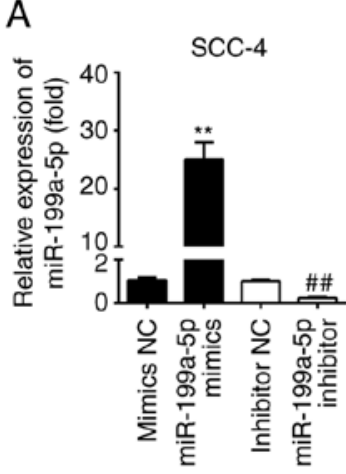

B

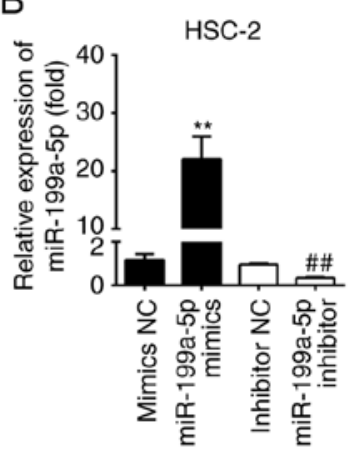

C

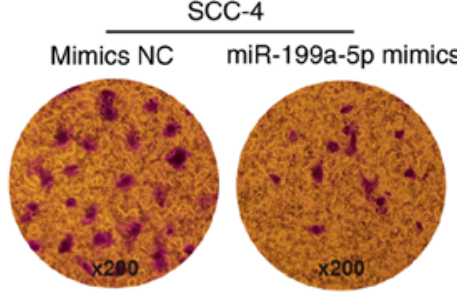

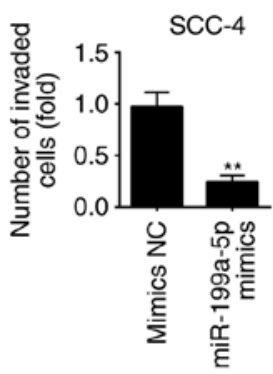

E

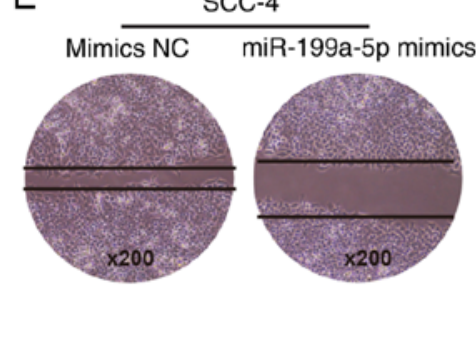

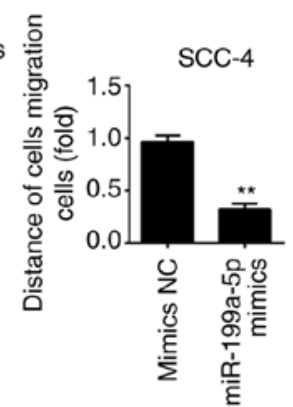

G

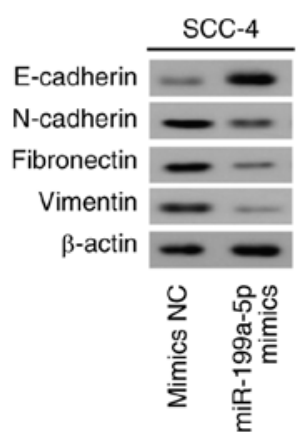

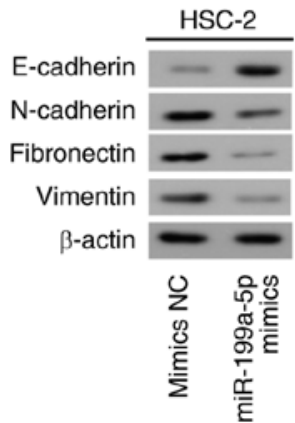

$\mathrm{F}$

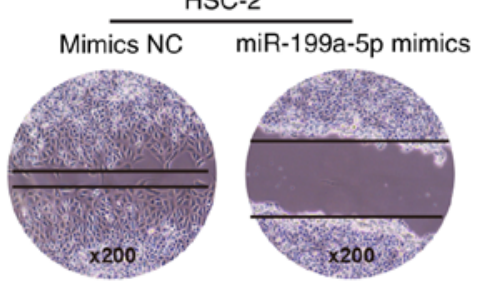

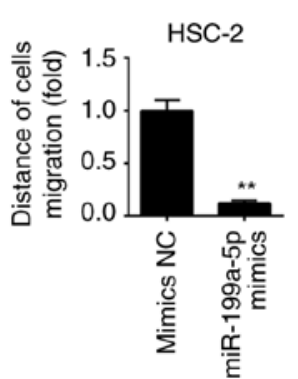

Figure 2. Overexpression of miR-199a-5p inhibits cell invasion and migration in vitro. (A and B) RT-qPCR was used to evaluate the transfection efficiency of miR-199a-5p mimics/inhibitor in SCC-4 and HSC-2 cells. ${ }^{* *} \mathrm{P}<0.01$ vs. mimics NC; ${ }^{\# \#} \mathrm{P}<0.01$ vs. inhibitor NC. (C and D) SCC-4 and HSC-2 cells were transfected with miR-199a-5p mimics or mimics NC, and cell invasion was evaluated using a Transwell invasion assay. (E and F) Cell migration was evaluated by wound-healing assay in SCC-4 and HSC-2 cells post-transfection with miR-199a-5p mimics or mimics NC. (G) Western blot analysis was performed to detect the epithelial-mesenchymal transition protein markers E-cadherin, N-cadherin, vimentin and fibronectin in SCC-4 and HSC-2 cells transfected with miR-199a-5p mimics or mimics NC. $\beta$-actin was used as an internal control. ${ }^{* *} \mathrm{P}<0.01 \mathrm{vs}$. mimics NC. Data are presented as the means \pm standard deviation of three independent experiments. miR-199a-5p, microRNA-199a-5p; NC, negative control.

these results indicated that miR-199a-5p may suppress SOX4 expression by targeting its 3'-UTR in OSCC.

Knockdown of SOX4 inhibits OSCC cell proliferation, invasion and migration. To explore the role of SOX4 in OSCC cells, SCC-4 and HSC-2 cells were transfected with si-SOX4 or si-Scramble, and cell proliferation, invasion and migration were evaluated using CCK-8, Transwell invasion and wound-healing assays, respectively. Firstly, the effects of si-SOX4 (si-SOX4-1, si-SOX4-2 and si-SOX4-3) on SOX4 expression in OSCC cells were analyzed. As shown in Fig. 4A and B, all three siRNAs significantly inhibited SOX4 expression in SCC-4 and HSC-2 cells compared with si-Scramble $(\mathrm{P}<0.01)$; si-SOX4-1 exhibited the strongest effect and was selected for subsequent experiments. As shown in Fig. 4C and D, knockdown of SOX4 markedly suppressed proliferation of SCC-4 and HSC-2 cells compared with
si-Scramble $(\mathrm{P}<0.05)$. Furthermore, cell invasion and migration were significantly inhibited in SCC- 4 and HSC-2 cells transfected with si-SOX4 ( $\mathrm{P}<0.01$; Fig. 4E-G). These results indicated that SOX4 may act as an oncogene in OSCC via modulating cell proliferation, migration and invasion.

Overexpression of SOX4 rescues the suppressive effects of miR-199a-5p on OSCC cells. To further investigate whether SOX4 is a functional target of miR-199a-5p in OSCC cells, SCC-4 and HSC-2 cells were transfected with miR-199a-5p mimics/mimics NC or were co-transfected with miR-199a-5p mimics and pcDNA-SOX4/pcDNA-vector plasmids, and cell invasion and migration were determined using Transwell invasion and wound-healing assays, respectively. Firstly, the transfection efficiency of pcDNA-SOX4 was evaluated in SCC-4 and HSC-2 cells; SOX4 was significantly upregulated compared with in cells transfected with the pcDNA-vector 


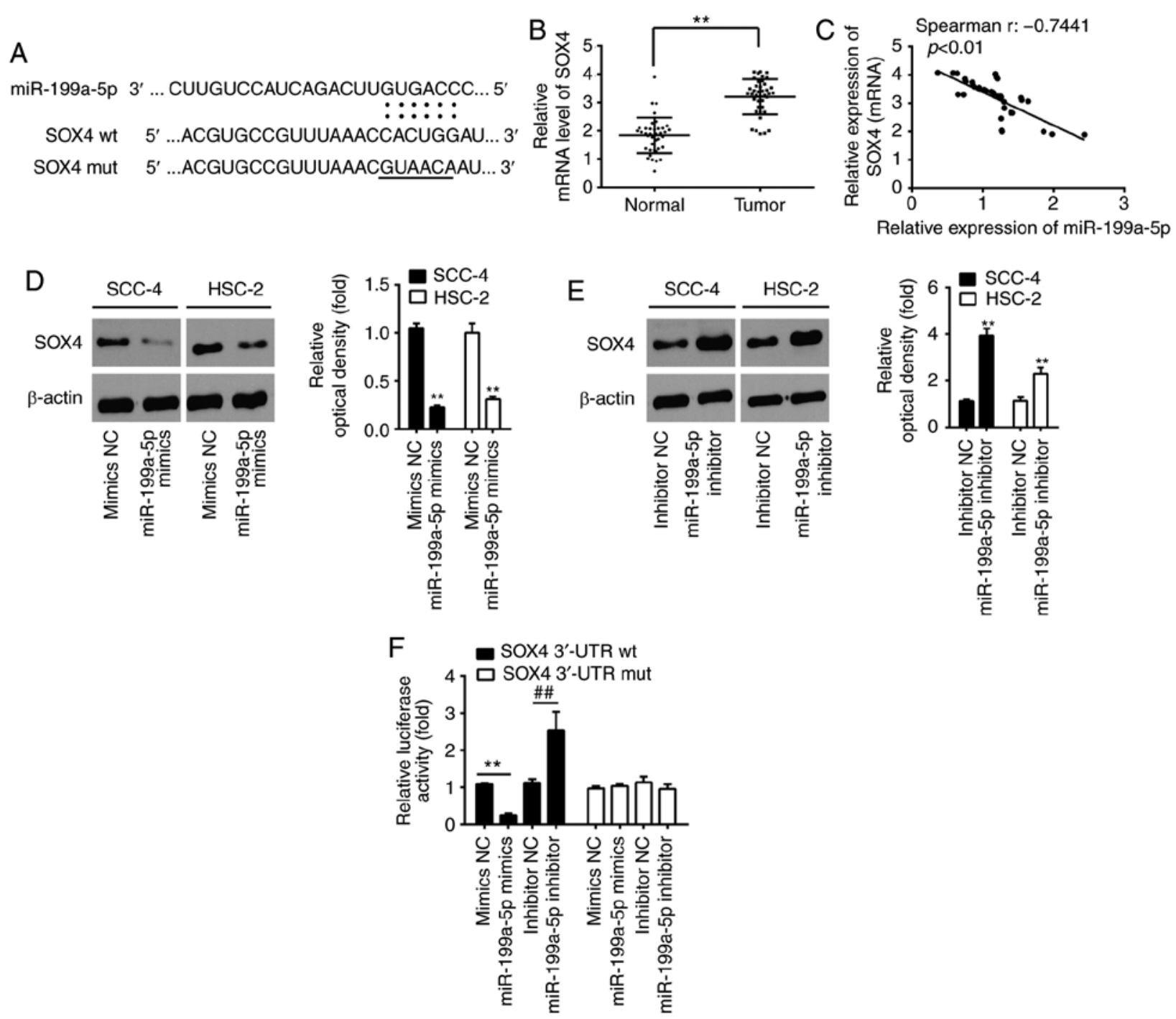

Figure 3. SOX4 is a target gene of miR-199a-5p in OSCC cells. (A) SOX4 3'-UTR region containing the wt or mut binding site for miR-199a-5p. (B) SOX4 was detected by reverse transcription-quantitative polymerase chain reaction in OSCC tissues and adjacent normal oral epithelial tissues ( $\mathrm{n}=40){ }^{* * *} \mathrm{P}<0.01$ vs. normal tissues. (C) Negative correlation between SOX4 and miR-199a-5p expression in patients with OSCC ( $r=-0.7441$, P<0.01). (D) SCC-4 and HSC-2 cells were transfected with miR-199a-5p mimics or mimics NC, and SOX4 protein expression was measured by western blot analysis. ${ }^{* *} \mathrm{P}<0.01$ vs. mimics NC. $\beta$-actin served as an internal control. (E) SOX4 was detected by western blot analysis in SCC-4 and HSC-2 cells transfected with miR-199a-5p inhibitor or inhibitor NC. ${ }^{* *} \mathrm{P}<0.01$ vs. inhibitor NC. (F) Relative luciferase activity of SOX4 wt or mut 3'-UTR in SCC-4 cells post-transfection with miR-199a-5p mimic/inhibitor or corresponding NC. ${ }^{* *} \mathrm{P}<0.01$ vs. mimics NC; ${ }^{\# \#} \mathrm{P}<0.01$ vs. inhibitor NC. Data are presented as the means \pm standard deviation of three independent experiments. 3'-UTR, 3'-untranslated region; miR-199a-5p, microRNA-199a-5p; mut, mutant; NC, negative control; OSCC, oral squamous cell carcinoma; SOX4, SRY-box 4; wt, wild type.

$(\mathrm{P}<0.01$; Fig. 5A). Subsequently, the results demonstrated that overexpression of miR-199a-5p markedly suppressed cell migration; however, upregulation of SOX4 significantly increased miR-199a-5p-mediated migration of SCC-4 and HSC-2 cells ( $\mathrm{P}<0.01$; Fig. 5B and C). Furthermore, the results confirmed that the suppressive effect of miR-199a-5p on cell invasion was rescued by SOX4 in SCC- 4 and HSC- 2 cells $(\mathrm{P}<0.01$; Fig. 5D and E). These data suggested that the suppressive effects of miR-199a-5p on cell migration and invasion may be rescued by SOX4 overexpression in OSCC cells.

\section{Discussion}

Previous studies have demonstrated that miR-199a-5p functions as a tumor suppressor gene or oncogene in numerous types of cancer, including human colorectal cancer and gastric cancer $(22,33)$. However, the roles of miR-199a-5p in OSCC remain elusive. In this study, the results demonstrated that miR-199a-5p was markedly downregulated in human OSCC tissues and cell lines, and low miR-199a-5p expression was associated with clinicopathological features and predicted poor overall survival in patients with OSCC. Furthermore, overexpression of miR-199a-5p suppressed the invasion and migration of OSCC cells through inhibiting the EMT process. In addition, SOX4 was identified as a target gene of miR-199a-5p in OSCC cells, and the suppressive effects of miR-199a-5p on cell migration and invasion were rescued by overexpression of SOX4 in OSCC cells.

It has been reported that miR-199a dysregulation is associated with the progression and pathogenesis of cancer, and previous studies have proposed conflicting roles for miR-199a in tumor progression and carcinogenesis. For example, a 

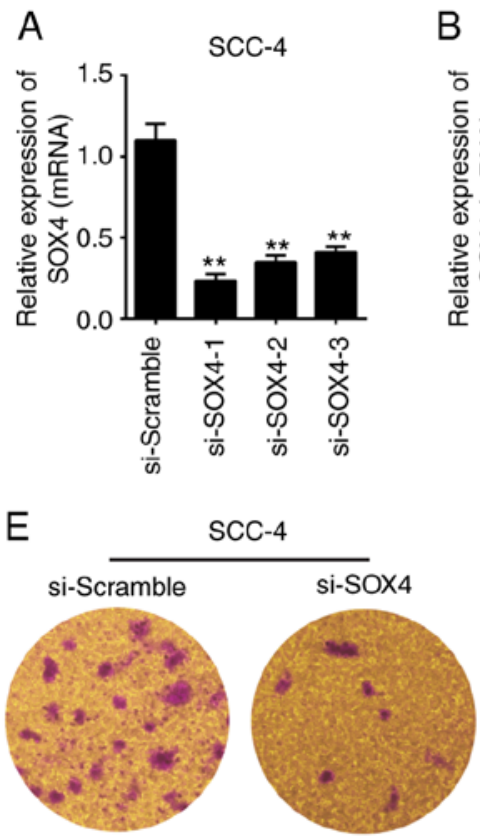

G

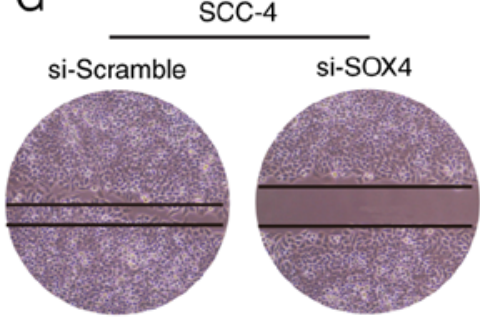

$\mathrm{B}$

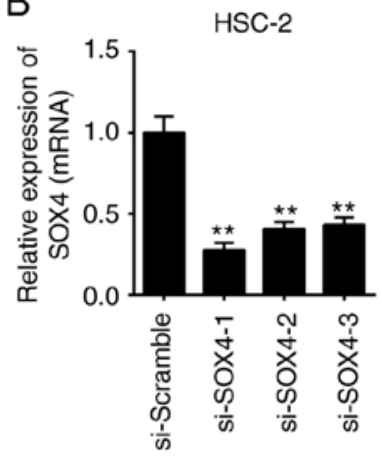

C

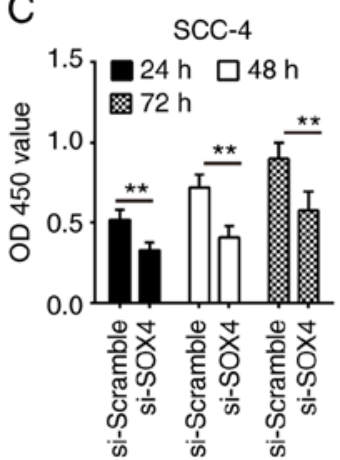

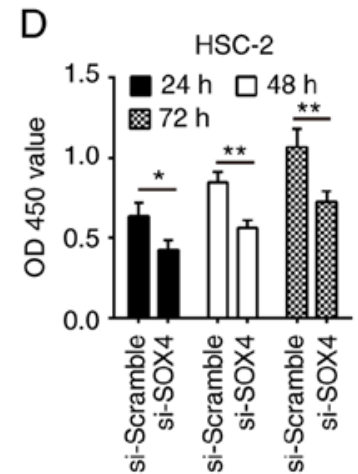

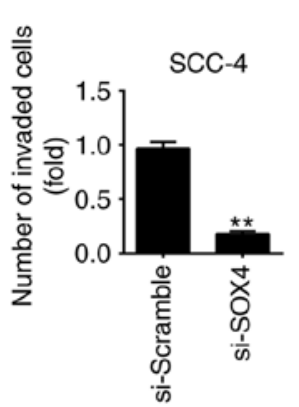

$\mathrm{F}$
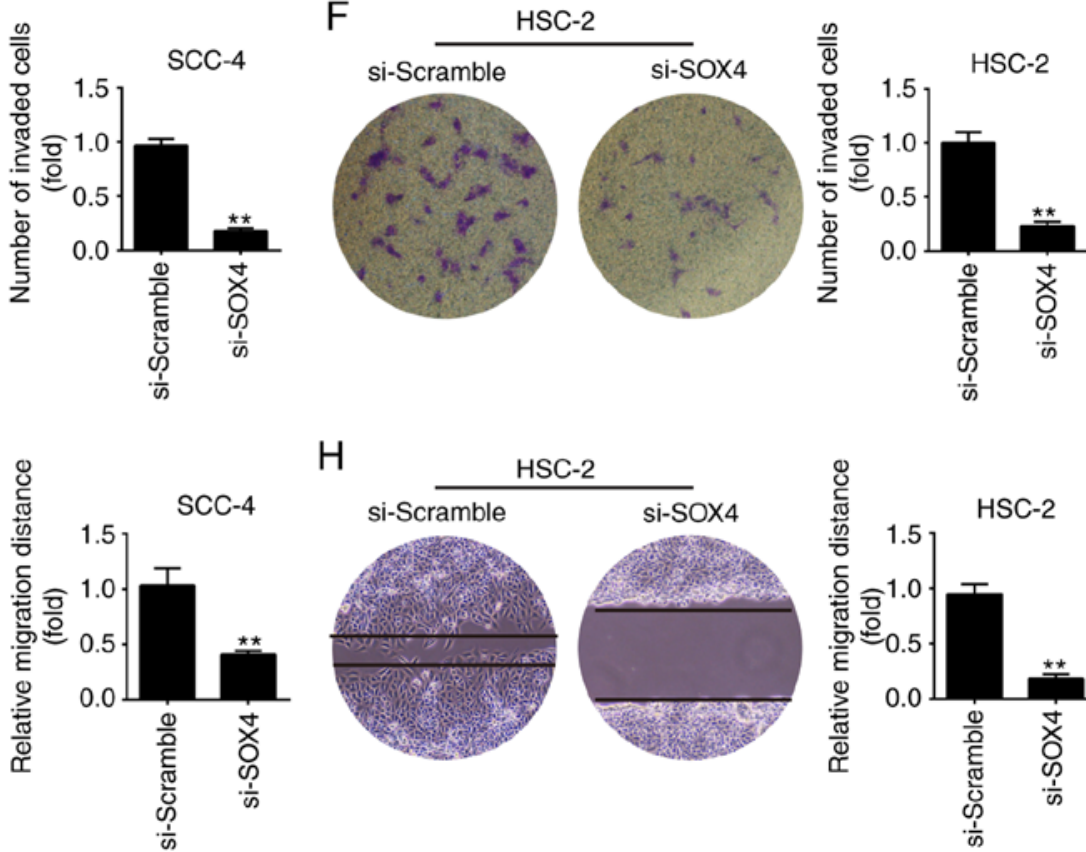

$\mathrm{H}$
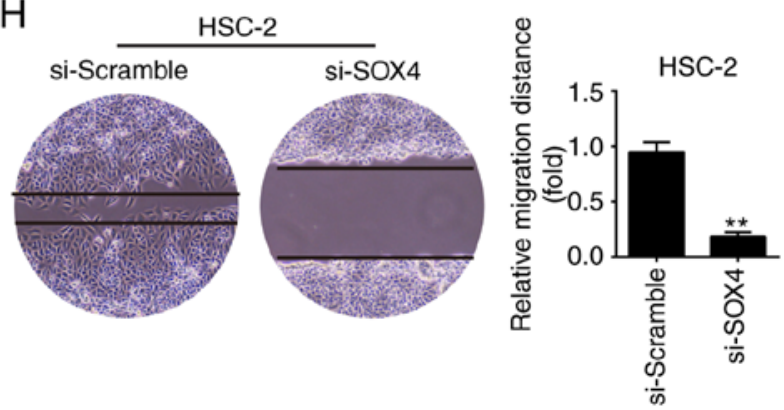

Figure 4. Knockdown of SOX4 suppresses OSCC cell proliferation, migration and invasion. (A and B) SCC-4 and HSC-2 cells were transfected with si-SOX4 (si-SOX4-1, si-SOX4-2 and si-SOX4-3) or si-Scramble, and the effects of si-SOX4 on SOX4 expression were evaluated by reverse transcription-quantitative polymerase chain reaction. (C and D) Cell proliferation was evaluated by Cell Counting Kit-8 assay in SCC-4 and HSC-2 cells transfected with si-SOX4 or si-Scramble. (E and F) Cell invasion was evaluated using Transwell invasion assay in SCC-4 and HSC-2 cells transfected with si-SOX4 or si-Scramble (magnification, x200). (G and H) SCC-4 and HSC-2 cells were transfected with si-SOX4 or si-Scramble, and cell migration was evaluated by wound-healing assay (magnification, $\mathrm{x} 200$ ). ${ }^{*} \mathrm{P}<0.05,{ }^{* *} \mathrm{P}<0.01$ vs. si-Scramble. Data are presented as the means \pm standard deviation of three independent experiments. OD, optical density; si, small interfering RNA; SOX4, SRY-box 4.

previous study demonstrated that miR-199a may act as a tumor suppressor in renal cancer (34), whereas another study documented that miR-199a may serve an oncogenic role in small cell carcinoma of the cervix (35). In addition, a previous study reported that miR-199a-5p attenuates proliferation and metastasis, and stem cell-like characteristics in breast cancer (36). However, little is currently known about the functional role of miR-199a-5p in OSCC. The present study performed RT-qPCR to investigate miR-199a-5p expression in OSCC tissues and adjacent normal oral epithelial tissues. The results revealed that miR-199a-5p was significantly downregulated in OSCC tissues compared with in normal oral epithelial tissues. Furthermore, miR-199a-5p expression in OSCC tissues with lymph node metastasis was lower than that in tissues without lymph node metastasis, thus suggesting that miR-199a-5p may serve an important role in the progression of OSCC. In addition, low expression of miR-199a-5p in patients with OSCC was associated with clinicopathological features and predicted a poor prognosis. Downregulation of miR-199a-5p was also confirmed in OSCC cell lines. These data suggested that miR-199a-5p may act as a tumor suppressor in OSCC tumorigenesis and may serve as a biomarker in OSCC diagnosis. This study also revealed that overexpression of miR-199a-5p significantly inhibited the migration and invasion of OSCC cells; however, the potential molecular mechanism requires further investigation.

EMT, which is characterized by the acquisition of a mesenchymal phenotype and loss of epithelial characteristics, serves a critical role in tumor metastasis and is associated with tumor recurrence $(14,37)$. EMT can be evaluated by measuring alterations in the expression levels of molecular markers, including $\mathrm{N}$-cadherin, E-cadherin and vimentin $(38,39)$. Previous studies reported that miR-199a-5p modulates metastasis via regulating the EMT process in various types of cancer, such as human gastric cancer and colorectal cancer $(40,41)$. In the present study, it was demonstrated that overexpression of miR-199a-5p 

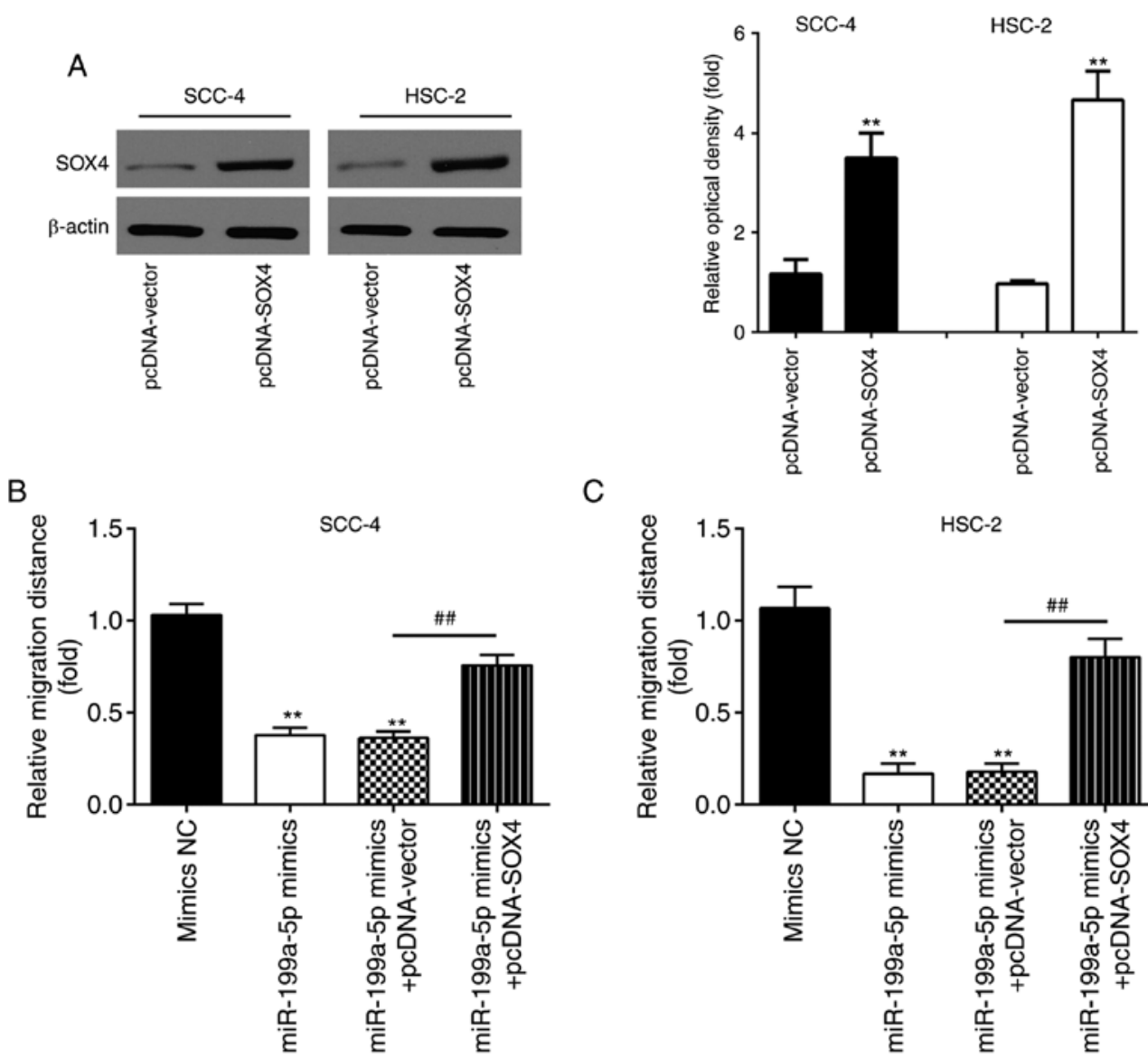

C
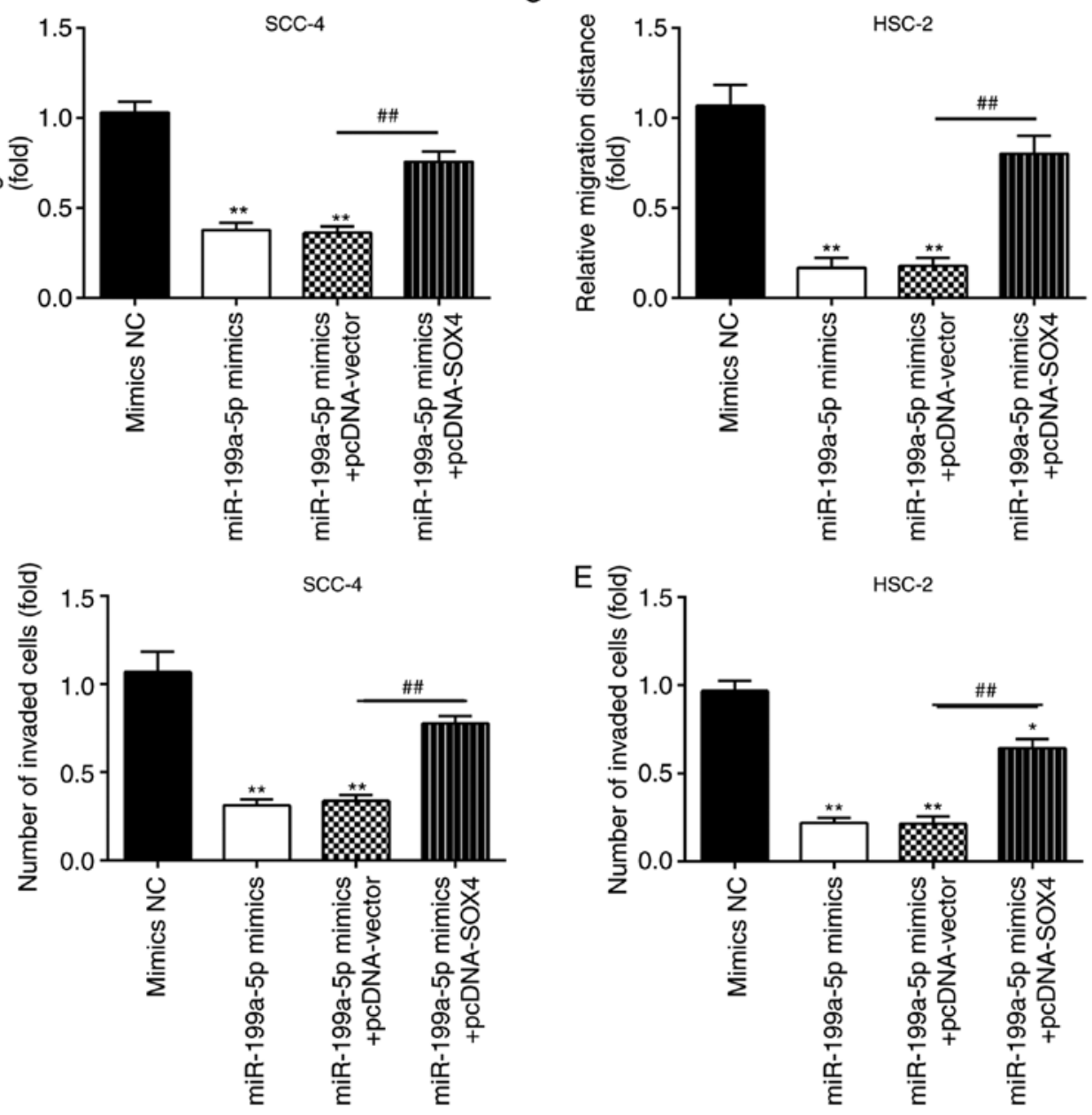

Figure 5. Overexpression of SOX4 rescues the suppressive effects of miR-199a-5p on oral squamous cell carcinoma cells. Cells were transfected with miR-199a-5p mimics/mimics NC or were co-transfected with miR-199a-5p mimics and pcDNA-SOX4/pcDNA-vector plasmids. (A) Western blot analysis was used to evaluate transfection efficiency of pcDNA-SOX4 in SCC-4 and HSC-2 cells. ${ }^{* *} \mathrm{P}<0.01$ vs. pcDNA-vector. (B and C) Cell migration was determined using a wound-healing assay in SCC-4 and HSC-2 cells. (D and E) Transwell invasion assay was used to measure cell invasion in SCC-4 and HSC-2 cells. ${ }^{* *} \mathrm{P}<0.01$ vs. mimics NC; ${ }^{\# /} \mathrm{P}<0.01$ vs. miR-199a-5p mimics + pcDNA-vector. Data are presented as the means \pm standard deviation of three independent experiments. miR-199a-5p, microRNA-199a-5p; NC, negative control; SOX4, SRY-box 4.

upregulated E-cadherin, and downregulated N-cadherin, vimentin and fibronectin in OSCC cell lines. These data indicated that miR-199a-5p may inhibit invasion and migration via suppressing EMT.

The transcription factor SOX4 has been demonstrated to induce EMT through modulating expression of enhancer of zeste 2 polycomb repressive complex 2 subunit, which acts as an epigenetic regulator $(12,13)$. SOX4 is an EMT-related gene that governs traditional EMT transcription factors, including
ZEB, Snail and Twist family members (13). Notably, SOX4 is upregulated in numerous types of human cancer, including esophageal cancer (42), endometrial cancer (43), gastric cancer (44), ovarian cancer (45) and osteosarcoma (46), thus suggesting that SOX4 may be a key oncogene influencing the progression and metastasis of tumors. Previous studies have reported that some miRNAs suppress metastasis in various types of cancer by targeting the EMT regulator SOX4 $(5,47)$. Additionally, numerous miRNAs have been 
revealed to regulate cell proliferation, invasion and metastasis by targeting SOX4 in human cancer, including miR-138, miR-129-2 and miR-204 (44,45). In this study, the results indicated that SOX4 may be a target gene of miR-199a-5p in OSCC cells. Correlation analysis also revealed a negative correlation between miR-199a-5p and SOX4 expression in tumor tissues. Furthermore, knockdown of SOX4 by siRNA suppressed OSCC cell proliferation, migration and invasion; SOX4 knockdown had similar effects to miR-199a-5p overexpression. Additionally, restoration of SOX4 reversed the inhibitory effects of miR-199a-5p on OSCC cells, suggesting that miR-199a-5p may act as a tumor suppressor through repressing the oncogene SOX4. Notably, there may be more targets for miR-199a-5p. In future studies, we aim to transfect OSCC cells with miR-199a-5p mimics or inhibitor and use a DNA chip to identify genes with altered expression and a miR-199a-5p binding sequence in the 3'-UTR. Furthermore, associated signaling pathways will also be investigated in the future.

In conclusion, the present findings demonstrated that miR-199a-5p was significantly downregulated in human OSCC tissues and cell lines. Overexpression of miR-199a-5p suppressed invasion and migration of OSCC cells through blocking the SOX4/EMT pathway. The identified miR-199a-5p/SOX4 axis may provide novel insights into the molecular mechanisms underlying the progression and metastasis of cancer, and targeting miR-199a-5p may be a potential therapeutic strategy for the treatment of OSCC in the future.

\section{Acknowledgements}

Not applicable.

\section{Funding}

No funding was received.

\section{Availability of data and materials}

All data generated or analyzed during this study are included in this published article.

\section{Authors' contributions}

DW, WW, BS, YZ, XY, GL and JY performed the experiments, contributed to data analysis and wrote the paper. DW, WW, BS, YZ, XY, GL and JY analyzed the data. YS designed the study, and contributed to data analysis and experimental materials. All authors read and approved the final manuscript.

\section{Ethics approval and consent to participate}

All individuals provided written informed consent for the use of human specimens for clinical research. The present study was approved by The First Affiliated Hospital of Xinxiang Medical University Ethics Committees.

\section{Patient consent for publication}

Not applicable.

\section{Competing interests}

The authors declare that they have no competing interests.

\section{References}

1. Andersen CL, Christensen LL, Thorsen K, Schepeler T, Sørensen FB, Verspaget HW, Simon R, Kruhøffer M, Aaltonen LA, Laurberg S and Ørntoft TF: Dysregulation of the transcription factors SOX4, CBFB and SMARCC1 correlates with outcome of colorectal cancer. Br J Cancer 100: 511-523, 2009.

2. Min R, Zun Z, Siyi L, Wenjun Y, Lizheng W and Chenping Z: Increased expression of Toll-like receptor-9 has close relation with tumour cell proliferation in oral squamous cell carcinoma. Arch Oral Biol 56: 877-884, 2011.

3. Zhang H, Xia J, Wang K and Zhang J: Serum autoantibodies in the early detection of esophageal cancer: A systematic review. Tumour Biol 36: 95-109, 2015.

4. Genden EM, Ferlito A, Bradley PJ, Rinaldo A and Scully C: Neck disease and distant metastases. Oral Oncol 39: 207-212, 2003.

5. Hu F, Min J, Cao X, Liu L, Ge Z, Hu J and Li X: MiR-363-3p inhibits the epithelial-to-mesenchymal transition and suppresses metastasis in colorectal cancer by targeting Sox4. Biochem Biophys Res Commun 474: 35-42, 2016.

6. Penzo-Méndez AI: Critical roles for SoxC transcription factors in development and cancer. Int J Biochem Cell Biol 42: 425-428, 2010.

7. Lee CJ, Appleby VJ, Orme AT, Chan WI and Scotting PJ: Differential expression of SOX4 and SOX11 in medulloblastoma. J Neurooncol 57: 201-214, 2002.

8. Castillo SD, Matheu A, Mariani N, Carretero J, Lopez-Rios F, Lovell-Badge R and Sanchez-Cespedes M: Novel transcriptional targets of the SRY-HMG box transcription factor SOX4 link its expression to the development of small cell lung cancer. Cancer Res 72: 176-186, 2012.

9. Liu P, Ramachandran S, Ali Seyed M, Scharer CD, Laycock N, Dalton WB, Williams H, Karanam S, Datta MW, Jaye DL and Moreno CS: Sex-determining region Y box 4 is a transforming oncogene in human prostate cancer cells. Cancer Res 66: 4011-4019, 2006.

10. Liao YL, Sun YM, Chau GY, Chau YP, Lai TC, Wang JL, Horng JT, Hsiao M and Tsou AP: Identification of SOX4 target genes using phylogenetic footprinting-based prediction from expression microarrays suggests that overexpression of SOX4 potentiates metastasis in hepatocellular carcinoma. Oncogene 27: 5578-5589, 2008.

11. Medina PP, Castillo SD, Blanco S, Sanz-Garcia M, Largo C, Alvarez S, Yokota J, Gonzalez-Neira A, Benitez J, Clevers HC, et al: The SRY-HMG box gene, SOX4, is a target of gene amplification at chromosome $6 \mathrm{p}$ in lung cancer. Hum Mol Genet 18: 1343-1352, 2009.

12. Koumangoye RB, Andl T, Taubenslag KJ, Zilberman ST, Taylor CJ, Loomans HA and Andl CD: SOX4 interacts with EZH 2 and HDAC3 to suppress microRNA-31 in invasive esophageal cancer cells. Mol Cancer 14: 24, 2015.

13. Tiwari N, Tiwari VK, Waldmeier L, Balwierz PJ, Arnold P, Pachkov M, Meyer-Schaller N, Schübeler D, van Nimwegen E and Christofori G: Sox 4 is a master regulator of epithelial-mesenchymal transition by controlling Ezh 2 expression and epigenetic reprogramming. Cancer Cell 23: 768-783, 2013.

14. Kang Y and Massagué J: Epithelial-mesenchymal transitions: Twist in development and metastasis. Cell 118: 277-279, 2004.

15. Croce CM: Causes and consequences of microRNA dysregulation in cancer. Nat Rev Genet 10: 704-714, 2009.

16. Bartel DP: MicroRNAs: Target recognition and regulatory functions. Cell 136: 215-233, 2009.

17. Wu X, Zeng Y, Wu S, Zhong J, Wang Y and Xu J: MiR-204, down-regulated in retinoblastoma, regulates proliferation and invasion of human retinoblastoma cells by targeting CyclinD2 and MMP-9. FEBS Lett 589: 645-650, 2015.

18. Voorhoeve PM: MicroRNAs: Oncogenes, tumor suppressors or master regulators of cancer heterogeneity? Biochim Biophys Acta 1805: 72-86, 2010.

19. Wu BH, Luo M, Zhang DH and Zhou X: Deformation control and chatter suppression in 5-Axis milling of thin-walled blade. Adv Mater Res 188: 314-318, 2011. 
20. Shen Q, Cicinnati VR, Zhang X, Iacob S, Weber F, Sotiropoulos GC, Radtke A, Lu M, Paul A, Gerken G and Beckebaum S: Role of microRNA-199a-5p and discoidin domain receptor 1 in human hepatocellular carcinoma invasion. Mol Cancer 9: 227, 2010

21. Nam EJ, Yoon H, Kim SW, Kim H, Kim YT, Kim JH, Kim JW and Kim S: MicroRNA expression profiles in serous ovarian carcinoma. Clin Cancer Res 14: 2690-2695, 2008.

22. He XJ, Ma YY, Yu S, Jiang XT, Lu YD, Tao L, Wang HP, Hu ZM and Tao HQ: Up-regulated miR-199a-5p in gastric cancer functions as an oncogene and targets klotho. BMC Cancer 14: 218 , 2014.

23. Worley LA, Long MD, Onken MD and Harbour JW: Micro-RNAs associated with metastasis in uveal melanoma identified by multiplexed microarray profiling. Melanoma Res 18: 184-190, 2008.

24. Zhong J, Huang R, Su Z, Zhang M, Xu M, Gong J, Chen N, Zeng H, Chen X and Zhou Q: Downregulation of miR-199a-5p promotes prostate adeno-carcinoma progression through loss of its inhibition of HIF-1 $\alpha$. Oncotarget 8: 83523-83538, 2017.

25. Koshizuka K, Hanazawa T, Kikkawa N, Arai T, Okato A, Kurozumi A, Kato M, Katada K, Okamoto Y and Seki N Regulation of ITGA3 by the anti-tumor miR-199 family inhibits cancer cell migration and invasion in head and neck cancer. Cancer Sci 108: 1681-1692, 2017.

26. Livak KJ and Schmittgen TD: Analysis of relative gene expression data using real-time quantitative PCR and the 2(-Delta Delta C(T)) method. Methods 25: 402-408, 2001

27. Kim SY, Nam SY, Choi SH, Cho KJ and Roh JL: Prognostic value of lymph node density in node-positive patients with oral squamous cell carcinoma. Ann Surg Oncol 18: 2310-2317, 2011.

28. Bergers G, Brekken R, McMahon G, Vu TH, Itoh T, Tamaki K, Tanzawa K, Thorpe P, Itohara S, Werb Z and Hanahan D: Matrix metalloproteinase-9 triggers the angiogenic switch during carcinogenesis. Nat Cell Biol 2: 737-744, 2000.

29. Natalwala A, Spychal R and Tselepis C: Epithelial-mesenchymal transition mediated tumourigenesis in the gastrointestinal tract. World J Gastroenterol 14: 3792-3797, 2008

30. Dasgupta P, Kulkarni P, Majid S, Shahryari V, Hashimoto Y, Bhat NS, Shiina M, Deng G, Saini S, Tabatabai ZL, et al: MicroRNA-203 inhibits long noncoding RNA HOTAIR and regulates tumorigenesis through epithelial-to-mesenchymal transition pathway in renal cell carcinoma. Mol Cancer Ther 17: 1061-1069, 2018

31. Imani S, Wei C, Cheng J, Khan MA, Fu S, Yang L, Tania M, Zhang X, Xiao X, Zhang X and Fu J: MicroRNA-34a targets epithelial to mesenchymal transition-inducing transcription factors (EMT-TFs) and inhibits breast cancer cell migration and invasion. Oncotarget 8: 21362-21379, 2017

32. Ko YH, Kim EJ, Sun DS, Won HS and Ahn YH: Abstract 1466 : QKI, a miRNA-200 target gene, suppresses epithelial-to-mesenchymal transition in oral squamous cell carcinoma cells. Cancer Res 77: 1466, 2017.

33. Kim BK, Yoo HI, Kim I, Park J and Kim Yoon S: FZD6 expression is negatively regulated by miR-199a-5p in human colorectal cancer. BMB Rep 48: 360-366, 2015.
34. Tsukigi M, Bilim V, Yuuki K, Ugolkov A, Naito S, Nagaoka A, Kato T, Motoyama T and Tomita Y: Re-expression of miR-199a suppresses renal cancer cell proliferation and survival by targeting GSK-3 3 . Cancer Lett 315: 189-197, 2012.

35. Huang L, Lin JX, Yu YH, Zhang MY, Wang HY and Zheng M Downregulation of six MicroRNAs is associated with advanced stage, lymph node metastasis and poor prognosis in small cell carcinoma of the cervix. PLoS One 7: e33762, 2012.

36. Chen J, Shin VY, Siu MT, Ho JC, Cheuk I and Kwong A: miR-199a-5p confers tumor-suppressive role in triple-negative breast cancer. BMC Cancer 16: 887, 2016.

37. Nauseef JT and Henry MD: Epithelial-to-mesenchymal transition in prostate cancer: Paradigm or puzzle? Nat Rev Urol 8: 428-439, 2011

38. Yang $\mathrm{J}$ and Weinberg RA: Epithelial-mesenchymal transition: At the crossroads of development and tumor metastasis. Dev Cell 14: 818-829, 2008.

39. Zeisberg M and Neilson EG: Biomarkers for epithelial-mesenchymal transitions. J Clin Invest 119: 1429-1437, 2009

40. Zhao X, He L, Li T, Lu Y, Miao Y, Liang S, Guo H, Bai M, Xie H, Luo G, et al: SRF expedites metastasis and modulates the epithelial to mesenchymal transition by regulating miR-199a-5p expression in human gastric cancer. Cell Death Differ 21: 1900-1913, 2014

41. Hu Y, Liu J, Jiang B, Chen J, Fu Z, Bai F, Jiang J and Tang Z: MiR-199a-5p loss up-regulated DDR1 aggravated colorectal cancer by activating epithelial-to-mesenchymal transition related signaling. Dig Dis Sci 59: 2163-2172, 2014.

42. Kang M, Li Y, Liu W, Wang R, Tang A, Hao H, Liu Z and Ou H: miR-129-2 suppresses proliferation and migration of esophageal carcinoma cells through downregulation of SOX4 expression. Int J Mol Med 32: 51-58, 2013.

43. Huang YW, Liu JC, Deatherage DE, Luo J, Mutch DG, Goodfellow PJ, Miller DS and Huang TH: Epigenetic repression of microRNA-129-2 leads to overexpression of SOX4 oncogene in endometrial cancer. Cancer Res 69: 9038-9046, 2009.

44. Zhou X, Li L, Su J and Zhang G: Decreased miR-204 in H. pylori-associated gastric cancer promotes cancer cell proliferation and invasion by targeting SOX4. PLoS One 9: e101457, 2014.

45. Yeh YM, Chuang CM, Chao KC and Wang LH: MicroRNA-138 suppresses ovarian cancer cell invasion and metastasis by targeting SOX4 and HIF-1 $\alpha$. Int J Cancer 133: 867-878, 2013.

46. Wang J, Xu G, Shen F and Kang Y: miR-132 targeting cyclin E1 suppresses cell proliferation in osteosarcoma cells. Tumour Biol 35: 4859-4865, 2014

47. Li S, Qin X, Li Y, Zhang X, Niu R, Zhang H, Cui A, An W and Wang X: MiR-133a suppresses the migration and invasion of esophageal cancer cells by targeting the EMT regulator SOX4. Am J Transl Res 7: 1390-1403, 2015.

This work is licensed under a Creative Commons Attribution-NonCommercial-NoDerivatives 4.0 International (CC BY-NC-ND 4.0) License. 